Bull. Chem. Soc. Ethiop. 2017, 31(3), 411-422.

ISSN 1011-3924

(c) 2017 Chemical Society of Ethiopia and The Authors

Printed in Ethiopia

DOI: http://dx.doi.org/10.4314/bcse.v31i3.5

\title{
REMOVAL OF BASIC GREEN 5 BY CARBONACEOUS ADSORBENT: ADSORPTION KINETICS
}

\author{
Sultan Alam ${ }^{1}$, Noor Rehman ${ }^{2 *}$, Noor ul Amin ${ }^{3}$, Luqman Ali Shah ${ }^{4}$, Inamullah Mian ${ }^{1}$ and \\ Hidayat Ullah ${ }^{5}$ \\ ${ }^{1}$ Department of Chemistry, University of Malakand, 18800 Khyber Pakhtunkhwa, Pakistan \\ ${ }^{2}$ Department of Chemistry, Shaheed Banazir Bhutto University, 18000 Sheringal, Dir (Upper) \\ Khyber Pakhtunkhwa, Pakistan \\ ${ }^{3}$ Department of Chemistry, Abdul Wali Khan University, 23200 Khyber Pakhtunkhwa, Pakistan \\ ${ }^{4}$ National Centre of Excellence in Physical Chemistry, University of Peshawar, 25120 \\ Khyber Pakhtunkhwa, Pakistan \\ ${ }^{5}$ Institute of Chemical Sciences, University of Peshawar, 25000 Khyber Pakhtunkhwa, Pakistan
}

(Received August 21, 2017; Revised December 5, 2017; Accepted December 17, 2017)

\begin{abstract}
The Eucalyptus lenceolata wood was collected from Malakand division, Khyber Pakhtunkhwa Pakistan. Chemical activation of sample was conducted for surface efficiency. Batch studies were performed to address various experimental parameters like, contact time, temperature and adsorbent dosage for the removal of dye. For elemental analysis, surface morphology and for identification of different functional groups, energy dispersive spectroscopy (EDS), scanning electron microscopy (SEM) and Fourier transform infrared (FTIR) techniques were applied, respectively. Removal of dye (Basic Green 5) was studied on raw and activated samples by kinetics adsorption at different temperature. BET adsorption isotherm was used to characterize the surface area of the sample. Under the conditions investigated, a higher carbonization temperature promoted development of porous structures. Intraparticle diffusion, Elovich and Bhangam models were used for adsorption kinetics studies. From adsorption kinetic data thermodynamic parameters like $\Delta \mathrm{H}^{\neq}, \Delta \mathrm{S}^{\ddagger}$ and $\Delta \mathrm{E}^{\ddagger}$ were determined. The results show that the adsorption is spontaneous process. The endothermic nature of adsorptive process is due to the positive value of enthalpy. The negative entropy shows that acids molecules on the surface of adsorbent take an oriented position. The results shows that all the models were best fitted for these data of adsorption.
\end{abstract}

KEY WORDS: Activated carbon, Adsorption, SEM, EDS, FTIR, Surface area

\section{INTRODUCTION}

Over the last ten years, adsorption systems contain activated carbon (AC) has been well thought-out one of the greatest available technologies for removing both organic and inorganic trace contaminants $[1,2]$. When dyes are functional to the fibers they instruct a stable color. Almost all dye stuffs are made from the decontamination of coal tar [3, 4]. A variety of poisonous organic chemicals are potentially dangerous to human health and also to the earth and marine ecosystem. Aromatic compounds are present in waste effluents discharged from paint, solvent, petroleum, petrochemical, pharmaceutical, plastic, pesticide, iron and steel, paper and pulp industries. Adsorption processes using activated carbons have been found to be effective in the treatment of the wastewaters $[5,6]$. The adsorption method still waste the most outstanding as it can generally take away all types of organic pollutants and the effluent performance is appropriate for the reason that of a easy plan and simple operations. In particular, sorption on commercially accessible activated carbon is one of the most usual methods for the removal of pollutants from wastewater [7]. Furthermore, activated carbon can give an effective and financial division process to be working in the action of a variety of manufacturing effluents [8].

Activated carbons have adsorption ability that stems from their high surface area, porosity and surface chemical properties. These are the rich resources of adsorbents for waste water

*Corresponding author. E-mail: noorrehman@sbbu.edu.pk

This work is licensed under the Creative Commons Attribution 4.0 International License 
treatment. These absorbent are micro, meso and macroporous. The large size of adsorbate cannot approach to micropores they accommodate on meso and macropores [9].

The Basic Green 5 (BG-5) molecule having linear structure with molecular weight of 364.5 $\mathrm{g} / \mathrm{mol}$. Accidental intake of Basic Green 5 may be harmful to the health produces pain and decomposition of the alimentary tract with pain and vomiting, also death can occur due to in sufficiency of food eating due to severe narrowing of the esophagus and pylorus [10]. A quantity of difficulties encountered in elimination of dyes from wastewaters because dyes are stable molecules and oppose degradation. Marketable dyes are typically a mixture of large number complexes and its molecular structure and properties have not been reported so far. Dyes also vary commonly in chemical composition. In short, basic dyes are considered as one of the more challenging classes of dye which are considered toxic colorants. As a consequence, enhanced and cost effective technologies are required to remove them from textile effluents [11].

Rengaraj studied the agricultural solid waste for the removal of organic pollutant like phenol from wastewater by palm seed coating through activated carbon. The removal of phenol from aqueous solution on activated carbon was carried out under various conditions like contact time, concentration, $\mathrm{pH}$ and adsorbent dose [12].

The basic purpose of the present research work is to prepare an efficient adsorbent from low cost precursors which can remove the toxic substances from aqueous media.

\section{EXPERIMENTAL}

\section{Preparation of carbon adsorbent}

The source materials used were the wood of plants from stem of Eucalyptus lenceolata, which were collected and heated for 8 hours on a flame burner in a specially designed iron container with a passage for the emission of volatile matter. Carbon obtained (about half of the mass of wood used) was cooled in the container and ground with the help of pestle and mortar and passed through mesh 150-180 $\mu \mathrm{m}$. The carbon was leached with standard $0.2 \mathrm{~N}$ nitric acid and hydrochloric acid solutions in the ratio of $1: 1$, prepared from concentrated nitric acid and hydrochloric acid and taken for 24 hours at $25{ }^{\circ} \mathrm{C}$ with regular mixing. Then filtered and washed with distilled water until neutral $\mathrm{pH}$. The carbon was activated with organic solvent n-hexane and kept for 24 hours at $25{ }^{\circ} \mathrm{C}$ with regular mixing to remove the organic content form the sample, and then it was filtered. The obtained carbon was dried in an oven at $80 \pm 2{ }^{\circ} \mathrm{C}$. Then allowed to cool and kept under nitrogen atmosphere.

\section{Adsorbate}

Basic Green 5. The adsorbate solution was prepared from which different working solutions were prepared in double distilled water. The chemical structure of the dye is shown in Scheme 1 .

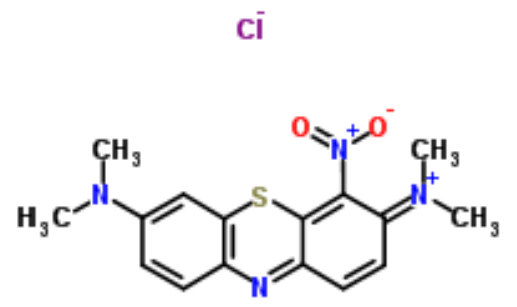

Scheme 1. Chemical structure of Basic Green 5.

Bull. Chem. Soc. Ethiop. 2017, 31(3) 
The trade name and some characteristics of the dye are: chemical name: Basic Green 5 (C.I. 52020), molecular formula: $\mathrm{C}_{16} \mathrm{H}_{17} \mathrm{ClN}_{4} \mathrm{O}_{2} \mathrm{~S}$, molecular weight: $364.86, \lambda_{\max } 657 \mathrm{~nm}$. Water solubility: soluble in water.

Analysis and characterization

Energy dispersive spectrum (EDS - INCA 200 Oxford Instruments) was used for elemental analysis on the adsorbent surface. SEM of the sample was obtained by mounting the sample on aluminum discs $(1 \mathrm{~cm} \times 0.25 \mathrm{~cm})$ and by using SEM-Model-JSM-5910, Japan JEOL. Fourier transmission infrared spectra of the carbon samples were obtained by using 8201PC Shimadzu Fourier Transform Infrared Spectrophotometer along with FTCOM-1 computer organize disc part. By BET- $\mathrm{N}_{2}$ adsorption the surface area of the sample was determined. The procedure was carried out manometrically at $-196{ }^{\circ} \mathrm{C}$ via surface area and pore size analyzer (Model: Quanta chrome NOVA 2200).

Adsorption studies

Equilibrium time. A $0.1 \mathrm{~g}$ of carbon plant sample was taken in reagent bottles and $10 \mathrm{~mL}$ of Basic Green 5 solution was added. Two initial concentrations of the dye sample were kept in reagent bottles and were shacked in thermo stated water bath shakers at $25{ }^{\circ} \mathrm{C}$ for different time $(0.5,1,2,4,6$ and 8 hours). The content of the reagent bottles was then filtered and the filtrate was studied for change in dye concentration using spectrophotometer. The quantity of dye adsorbed $\left(\mathrm{D}_{\Phi .} . \mathrm{mol} / \mathrm{g}\right)$ were determined with the help of the formula (1):

$D_{\phi}=\frac{D_{\circ}-D_{\sigma}}{W} V$

where $D_{o}$ is initial concentration and $D_{\sigma}$ is equilibrium concentration of dye $\left(\mathrm{mol} \mathrm{L}^{-1}\right)$ in that order, $\mathrm{V}$ is volume and $\mathrm{W}$ is weight of adsorbent.

Adsorption kinetic study. A $0.1 \mathrm{~g}$ adsorbent and $10 \mathrm{~mL}$ of dye solution were taken in reagent bottles. The mixture was shacked at 20,30 and $40{ }^{\circ} \mathrm{C}$ for the duration of $10-40 \mathrm{~min}$. Then filtered and the clear filtrate was examined for change in concentration by spectrophotometer. The dye adsorbed $\left(D_{\Phi} . \mathrm{mol}_{\mathrm{g}} \mathrm{g}^{-1}\right)$ was then determined by using the above-mentioned formula.

\section{RESULTS AND DISCUSSION}

\section{Surface area}

BET procedure was used to determine surface area of Eucalyptus lenceolata. It is based on multilayer adsorption of nitrogen gas on carbon surface and gives a base to explore the micro porous surface area of carbon. This method is support on monolayer adsorption of Langmuir isotherm exceeds to multilayer adsorption with assumptions: (1) $\mathrm{N}_{2}$ molecules accumulate on adsorbent in layers. (2) There are no intra molecular attractive forces. (3) Langmuir model can be explained each adsorbed layer. Surface area was calculated by using BET Equation 2 [13]:

$\frac{1}{v\left[\left(\frac{P o}{P}\right)-1\right]}=\frac{c-1}{v_{m} c}\left(\frac{p}{p o}\right)+\frac{1}{v_{m} c}$ 
The relative diffusion pressure of dye is $p$ and $p_{o}, v$ is the quantity of gas adsorbed at the surface and $v_{\mathrm{m}}$ is amount of unilayer $\mathrm{N}_{2}$ adsorbed and $C$ is constant.

$c=\exp \left(\frac{E_{1}-E_{L}}{R T}\right)$

The heat for first adsorb layer of sorption is $\mathrm{E}_{1}$ and $\mathrm{E}_{\mathrm{L}}$ is for onward layers.

To find adsorption isotherm used Equation 1 plotting $1 / v\left[\left(p_{o} / p\right)-1\right]$ against $\varphi=p / p_{o}$. intercept I and slope A is used to calculate the unilayer adsorbed $\mathrm{N}_{2}, v_{\mathrm{m}}$, and the constant $C$ by following equation.

$v_{m}=\frac{1}{A+I}$

$c=1+\frac{A}{I}$

The total specific surface area is given by

$S_{B E T, \text { total }}=\frac{\left(v_{m} N_{S}\right)}{V}$

The units of molar volume of $\mathrm{N}_{2}$ gas is $v_{\mathrm{m}}$

$S_{B E T}=\frac{S_{\text {total }}}{a}$

where $\mathrm{N}=$ Avogadro number, $\mathrm{S}$ is cross section of $\mathrm{N}_{2}$ gas, $\mathrm{M}$ is the molar volume of adsorbate gas and $\mathrm{a}$ is the adsorbent mass $(\mathrm{g})$.

Surface area of carbon samples were obtained by plotting 1/W $\left[\left(p_{o} / \mathrm{p}\right)-1\right]$ against $p / p_{o}$ of the $\mathrm{N}_{2}$ adsorption and were found to increase from 150 to $355 \mathrm{~m}^{2} \mathrm{~g}^{-1}$ for Eucalyptus lenceolata. The results show that the surface area of raw sample is $475 \mathrm{~m}^{2} \mathrm{~g}^{-1}$ greater than the activated samples $399 \mathrm{~m}^{2} \mathrm{~g}^{-1}$. During chemical changes the surface became neat and the foreign substances were removed and the surface becomes suitable for the adsorption of basic dye that is the sample surface area increase. Surface of carbon with non-polarity at high temperature also favor for high surface area, groups are removed and surface become homogeneous [14]. Eisazadeh studied specific surface area and pore structure and its main characteristics in determining its chemical and physical contacts. Due to this fact most of the chemical reactions occur in the surface. In the same way, the analysis of physical properties such as permeability requires an exact measurement of specific surface area and the pore structure. One of the most familiar method for determining the surface area as known is BET method [15].

\section{EDS/SEM}

The Elemental analysis showed that carbon and oxygen is an abundant in raw and activated samples of Eucalyptus lenceolata. However in the raw Eucalyptus lenceolata a small percent of calcium is also detected as shown in Table 1.

SEM was used to identify the characteristic morphologies of Eucalyptus lenceolata. The Scanning electron micrograph showed porosity of carbon as shown in Figure 1. Goldstein studied the EDS spectroscopy is a valuable characterization for elemental analysis in materials and medical science. Modern research indicates that a high-energy resolution EDS is necessary for use within the transmission electron microscope. Si-based semiconductor detectors are used for X-ray detection in the characteristic of EDS systems of electron microscopes [16]. 
Table 1. Elemental composition of raw carbon and activated carbon.

\begin{tabular}{|c|c|c|c|c|}
\hline Element & $\begin{array}{c}\text { Weight \% } \\
\text { raw carbon }\end{array}$ & $\begin{array}{c}\text { Weight \% } \\
\text { activated carbon }\end{array}$ & $\begin{array}{c}\text { Atomic \% } \\
\text { raw carbon }\end{array}$ & $\begin{array}{c}\text { Atomic \% } \\
\text { activated carbon }\end{array}$ \\
\hline $\mathrm{C}$ & 78.16 & 72.8 & 83.0 & 78.1 \\
\hline $\mathrm{O}$ & 20.9 & 27.2 & 16.7 & 21.9 \\
\hline $\mathrm{K}$ & 0.40 & - & 0.13 & - \\
\hline $\mathrm{Ca}$ & 0.68 & - & 0.22 & - \\
\hline Total & 100 & 100 & 100 & 100 \\
\hline
\end{tabular}
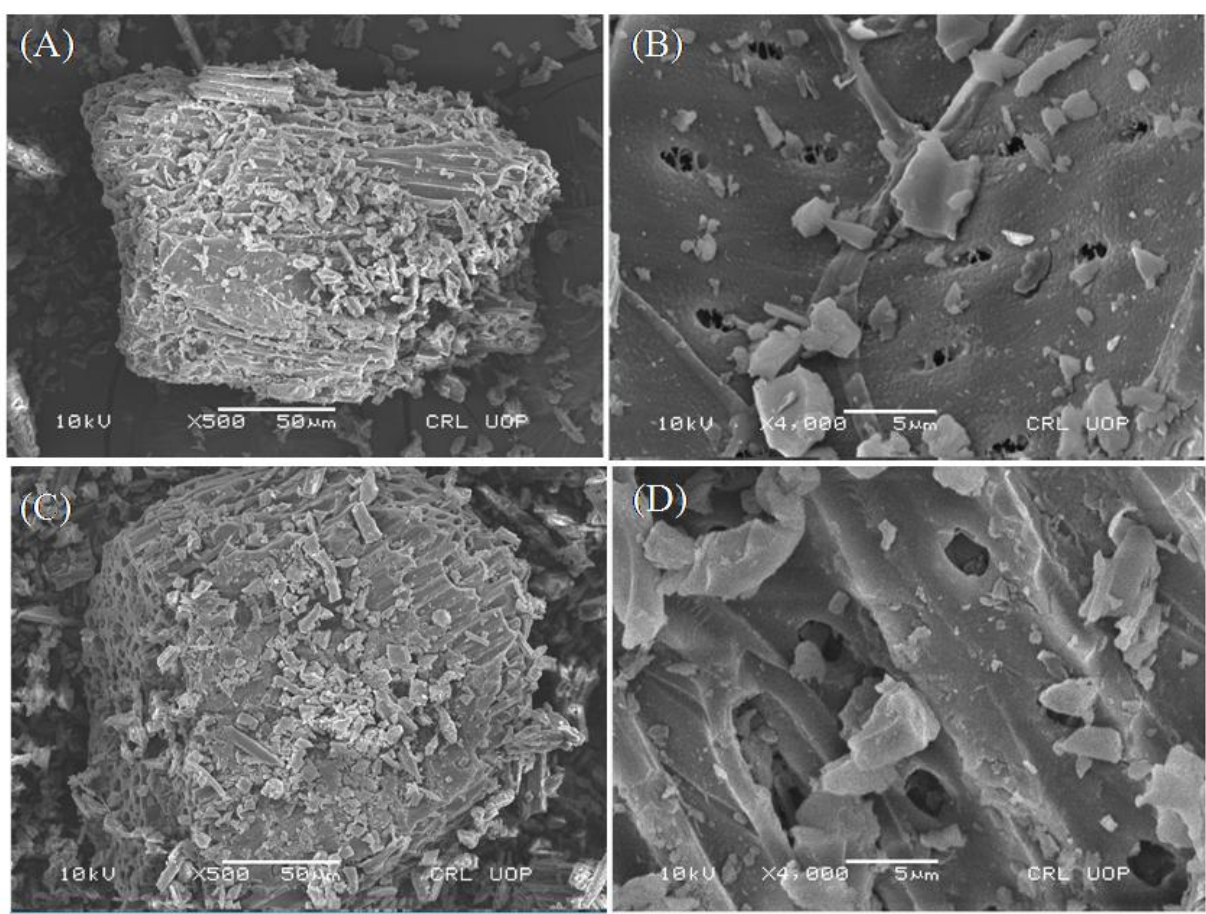

Figure 1. Scanning electron micrographs of (A) raw carbon with (X500), (B) raw carbon with $\mathrm{X} 4000,(\mathrm{C})$ activated carbon with X500) and (D) activated carbon with X4000.

FTIR

FTIR spectra of carbon of activated and raw Eucalyptus lenceolata are shown in Figure 2. The regions 1199,1190 and $1166 \mathrm{~cm}^{-1}$ in the spectra is due to the presence of $(\mathrm{C}-\mathrm{O})$ group stretching in raw carbon prepared from Eucalyptus lenceolata [17]. This region can be seen in spectrum of raw and activated Eucalyptus lenceolata samples. Eucalyptus lenceolata show $\mathrm{C}=\mathrm{C}$ group present at 1614 and $1647 \mathrm{~cm}^{-1}$ in raw carbon. The activated carbon show $\mathrm{C}=\mathrm{O}$ band on 1716 , and $1697 \mathrm{~cm}^{-1} . \mathrm{C}=\mathrm{C}$ show stretching bonds in benzene rings band on $1558 \mathrm{~cm}^{-1}$. The $(\mathrm{C}-\mathrm{O})$ group stretching band on 1188,1172 and $1151 \mathrm{~cm}^{-1}$. Group $\mathrm{S}=\mathrm{O}$ stretching which is present on $1022 \mathrm{~cm}^{-1}$ on activated carbon prepared from Eucalyptus lenceolata. The peaks in the region $1500-1600 \mathrm{~cm}^{-1}$ are mainly due to $\mathrm{C}=\mathrm{C}$ stretching bonds in benzene rings [18]. $\mathrm{C}=\mathrm{O}$ represent 
stretching which indicate the presence of oxygen containing functional groups such as carboxyl's, phenols and ethers of the type $\mathrm{C}_{6} \mathrm{H}_{5}-\mathrm{O}-\mathrm{CH}_{3}$ or $-\mathrm{CH}_{2}-\mathrm{O}-\mathrm{CH}_{3}$. Sharp bands in the region $1000-1100 \mathrm{~cm}^{-1}$, indicate that mineral matters were present in all the spectra's of all the two samples. Khare also studied Fourier transform infrared spectroscopy, Mattson 1000 spectrometer was used for the identification of different functional groups on the sample surface. The absorbance data were processed for the number wave range from 4000 to $400 \mathrm{~cm}^{-1}$ by means of the fundamental software [19].
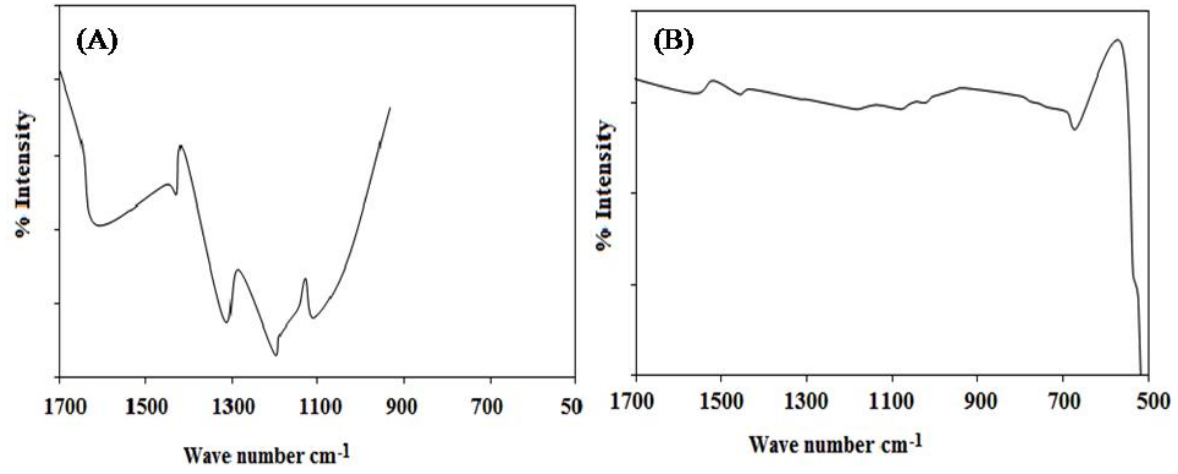

Figure 2. FTIR spectra of (A) raw carbon and (B) activated carbon.

\section{Adsorption studies}

Equilibration time and adsorption kinetics. The adsorption equilibrium time of basic dye on Eucalyptus lenceolata carbon was studied at $25{ }^{\circ} \mathrm{C}$ for a period of $0.5,1,2,4,6$ and 8 hours. The parameters of rate equations for Basic Green 5 onto raw carbon and activated carbon are given in Tables 2 and 3, respectively.

Table 2. Comparison of the parameters of rate equations for Basic Green 5 onto raw carbon.

\begin{tabular}{|c|c|c|c|c|}
\hline \multirow{2}{*}{ Kinetic model } & \multirow{2}{*}{ Parameter } & \multicolumn{3}{|c|}{ Adsorption temperature } \\
\cline { 2 - 5 } & & $20^{\circ} \mathrm{C}$ & $30{ }^{\circ} \mathrm{C}$ & $40{ }^{\circ} \mathrm{C}$ \\
\hline \multirow{2}{*}{ Elovich } & $\mathrm{A}_{\mathrm{E}}\left(\mathrm{g} \mathrm{mg}^{-1}\right)$ & 5.824 & 4.399 & 2.519 \\
\cline { 2 - 5 } & $\mathrm{R}^{2}$ & 0.8404 & 0.9474 & 0.6863 \\
\hline \multirow{2}{*}{$\begin{array}{c}\text { Intraparticle } \\
\text { diffusion }\end{array}$} & \left.${\mathrm{C}\left(\mathrm{mg} \mathrm{g}^{-1}\right)}^{-1 / 2}\right)$ & 7.2191 & 7.018 & 6.8686 \\
\cline { 2 - 5 } & $\mathrm{K}_{\mathrm{id}}\left(\mathrm{mg} \mathrm{g}^{-1} \mathrm{~min}^{-1 / 2}\right.$ & 0.0148 & 0.0186 & 0.0348 \\
\cline { 2 - 5 } Bangham & $\mathrm{R}^{2}$ & 0.9649 & 0.9832 & 0.8158 \\
\cline { 2 - 5 } & $\mathrm{A}$ & -0.3173 & -0.3229 & -0.5389 \\
\cline { 2 - 5 } & $\mathrm{K}_{\mathrm{O}}$ & 1.934 & 2.303 & 0.606 \\
\hline
\end{tabular}

The equilibrium was reached up to 4 hours and then become plateau. It was concluded that equilibration time 4 hours is maximum time to cover the entire surface. From equilibration time study the solution range for the adsorption kinetics was arranged and adsorption of dye was study at 20, 30 and $40{ }^{\circ} \mathrm{C}$ shown in Figure 3 for all the raw and activated samples of Eucalyptus lenceolata. In first $15 \mathrm{~min}$ the adsorption process was fast and then decreased due to the maximum diffusion. With increase in adsorption temperature adsorption of basic dye on carbon increases showing that the nature of process is endothermic. Ho studied the equilibrium 
adsorption isotherm is basically significant for adsorption systems. Equilibrium studies give the ability of the adsorbent and describe the adsorption isotherm by constants whose values convey the surface properties of the adsorbent. Equilibrium relationships between adsorbent and adsorbate are determined by adsorption isotherms, typically the ratio between the amount adsorbed and that remaining in the solution at a constant temperature at equilibrium. The major interest of this study was to investigate sorption of basic dye [20].

Table 3. Comparison of the parameters of rate equations for Basic Green 5 onto activated carbon.

\begin{tabular}{|l|l|l|l|l|}
\hline \multirow{2}{*}{ Kinetic model } & \multirow{2}{*}{ Parameter } & \multicolumn{3}{|c|}{ Adsorption temperatures } \\
\cline { 3 - 5 } & & $20{ }^{\circ} \mathrm{C}$ & $30{ }^{\circ} \mathrm{C}$ & $40{ }^{\circ} \mathrm{C}$ \\
\hline \multirow{2}{*}{ Elovich } & $\mathrm{A}_{\mathrm{E}}\left(\mathrm{g} \mathrm{mg}^{-1}\right)$ & 5.934 & 5.241 & 2.272 \\
\cline { 2 - 5 } & $\mathrm{R}^{2}$ & 0.9952 & 0.7197 & 0.7571 \\
\hline \multirow{3}{*}{$\begin{array}{l}\text { Intraparticle } \\
\text { diffusion }\end{array}$} & $\mathrm{C}\left(\mathrm{mg} \mathrm{g}^{-1}\right)$ & 3.5369 & 3.6061 & 3.5447 \\
\cline { 2 - 5 } & $\mathrm{K}_{\text {id }}\left(\mathrm{mg} \mathrm{g}^{-1} \mathrm{~min}^{-1 / 2}\right)$ & 0.0133 & 0.0169 & 0.0383 \\
\cline { 2 - 5 } & $\mathrm{R}^{2}$ & 0.967 & 0.8794 & 0.8909 \\
\hline \multirow{3}{*}{ Bangham } & $\mathrm{A}^{2}$ & -0.0398 & -0.0493 & -0.0651 \\
\cline { 2 - 5 } & $\mathrm{K}_{\mathrm{O}}$ & 6.218 & 6.241 & 6.218 \\
\cline { 2 - 5 } & $\mathrm{R}^{2}$ & 0.9972 & 0.7141 & 0.9664 \\
\hline
\end{tabular}
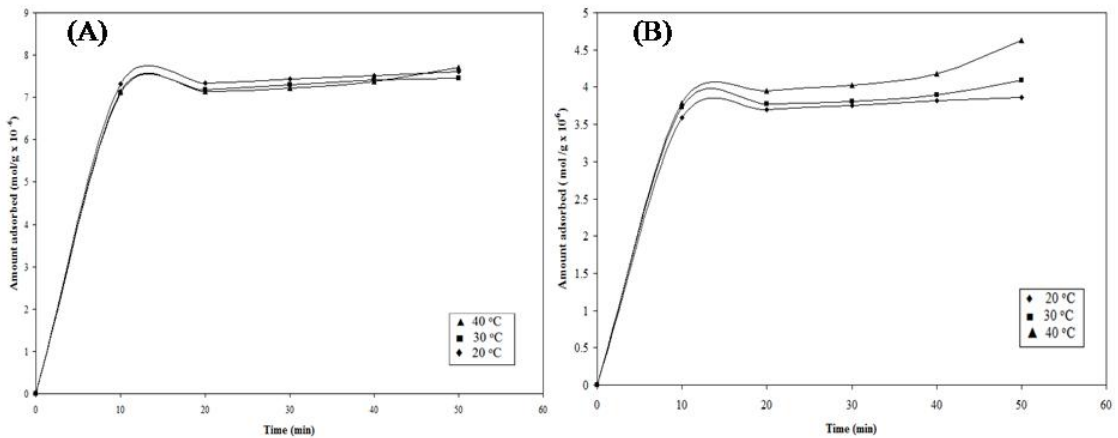

Figure 3. Adsorption kinetics of Basic Green 5 on (A) raw carbon and (B) activated carbon.

Adsorption kinetics

From the adsorption of (Basic Green-5) on carbon of woody plants (Eucalyptus lenceolata) the rate constant was determined by using first order rate equation:

$\ln \mathrm{D}_{\sigma}=\ln \mathrm{D}_{\mathrm{o}}-\mathrm{k}_{\mathrm{ad}} \mathrm{t}$

$D_{o}$ is initial and $D_{\sigma}$ is the equilibrium concentration of dye $\left(\mathrm{mol} \mathrm{L}^{-1}\right)$ and $\mathrm{k}_{\mathrm{ad}}$ stands for the rate constant. Rate constants were calculated from the straight line plots of $\ln \mathrm{D}_{\sigma}$ vs. $t$ at different temperatures as shown in Table 4. The values for rate constant increased with increasing experimental temperature. From the first order rate equation the $\mathrm{R}^{2}$ value $(0.8-0.99)$ closer to 1 , fit with adsorption literature.

The activation energy was determined by using the Arrhenius straight line equation in the following form: 
$\ln \frac{\mathrm{k}_{2}}{\mathrm{k}_{1}}=\frac{\mathrm{E}_{\mathrm{a}}}{\mathrm{R}}\left[\frac{\mathrm{T}_{2}-\mathrm{T}_{1}}{\mathrm{~T}_{1} \mathrm{~T}_{2}}\right]$

$\mathrm{E}_{\mathrm{a}}$ indicates energy of activation, rate constants are $\mathrm{k}_{1}$ and $\mathrm{k}_{2}$, gas constant $\mathrm{R}$ and temperature $\mathrm{T}$. The activation energies calculated for dye adsorbed on carbon are given in Table 4 . The energies of activation for the dye adsorbed at various temperatures were found to $25.1 \mathrm{~kJ} \mathrm{~mol}^{-1}$ for raw carbon while $48.2 \mathrm{~kJ} \mathrm{~mol}^{-1}$ for activated carbon of Basic Green 5. The rate of reaction of Basic Green 5 on raw carbon is high and the rate of reaction of Basic Green 5 on activated carbon is low. From activation energies, different thermodynamic parameters like $\Delta \mathrm{H}^{\#}$ and $\Delta \mathrm{S}^{\#}$ are determined (Table 4) the equations are given [21]:

$\Delta \mathrm{H}^{\#}=\Delta \mathrm{E}^{\#}-\mathrm{RT}$

$\Delta \mathrm{S}^{\neq}=\mathrm{R}\left[\ln \frac{\mathbf{k h}}{\mathrm{k}_{\mathrm{B}}^{\mathrm{T}}}+\frac{\Delta \mathrm{H}^{\neq}}{\mathrm{RT}}\right]$

where $\mathbf{k}, \mathrm{k}_{\mathrm{B}}$, h are rate constant, Boltzmann constant and Planck's constant respectively.

$\Delta \mathrm{H}^{\#}$ for the dye adsorption on raw and activated carbon of Eucaliptus lenceolata are shown in Table 4; Basic Green 5: 22.5 on activated carbon at $40{ }^{\circ} \mathrm{C}$, and 45.6 on raw carbon at $40{ }^{\circ} \mathrm{C}$. The positive values of $\Delta \mathrm{H}^{\#}$ show the endothermic nature of the process. The entropy of activation $\left(\Delta \mathrm{S}^{\#}\right)$ for the dye adsorption on carbon is also shown in Table 4; and negative values of the entropy revealed that the process is an order. Khaiary studied at higher concentrations the saturation of the adsorption sites, the rate constant of adsorption on sample surface. With the passage of time the remaining vacant surface sites are difficult to be occupied due to repulsive forces between adsorbate and adsorbent surface. Increase in temperature favor to increase in adsorption up to some extant [22].

Table 4. Thermodynamic constants for removal of basic dyes onto carbon prepared from the wood of Eucalyptus lenceolata.

\section{Elovich model}

\begin{tabular}{|c|c|c|c|c|c|c|c|c|c|c|}
\hline \multirow{2}{*}{ Sample } & \multicolumn{3}{|c|}{$\mathrm{k}\left(\mathrm{min}^{-1}\right)$} & \multirow{2}{*}{$\begin{array}{c}\Delta \mathrm{E}^{\neq} \\
\left(\mathrm{kJ} \cdot \mathrm{mol}^{-1}\right)\end{array}$} & \multicolumn{3}{|c|}{$\Delta \mathrm{H}^{\ddagger}\left(\mathrm{kJ} \cdot \mathrm{mol}^{-1}\right)$} & \multicolumn{3}{|c|}{$\Delta \mathrm{S}^{\ddagger}\left(\mathrm{kJ} \cdot \mathrm{mol}^{-1} \mathrm{~K}^{-1}\right)$} \\
\hline & $20^{\circ} \mathrm{C}$ & $30^{\circ} \mathrm{C}$ & $40^{\circ} \mathrm{C}$ & & $20^{\circ} \mathrm{C}$ & $30^{\circ} \mathrm{C}$ & $40^{\circ} \mathrm{C}$ & $20^{\circ} \mathrm{C}$ & $30^{\circ} \mathrm{C}$ & $40^{\circ} \mathrm{C}$ \\
\hline Raw & 0.0133 & 0.0137 & 0.0252 & 25.1 & 22.7 & 22.6 & 22.5 & -0.237 & -0.240 & -0.238 \\
\hline Activated & 0.0015 & 0.0021 & 0.0052 & 48.2 & 45.7 & 45.7 & 45.6 & -0.215 & -0.179 & -0.177 \\
\hline
\end{tabular}

Elovich model is expressed in linear form as [23].

$\mathrm{D}_{\varphi}=1 / \mathrm{A} \ln (\mathrm{CD})+1 / \mathrm{A} \ln (\mathrm{t})$

Straight lines were achieved by plotting $\mathrm{D}_{\Phi}$ versus $\ln (\mathrm{t})$ with slope " $1 / \mathrm{A}$ " and intercept " $1 / \mathrm{A}$ lnCD" shown in Figure 4. The values of " $A$ " decreases from $20^{\circ} \mathrm{C}$ in $\left(\mathrm{g} \mathrm{mg}^{-1}\right)$ to $40{ }^{\circ} \mathrm{C}$ in $(\mathrm{g}$ $\mathrm{mg}^{-1}$ ) shows an evident, that high temperature favored adsorption (Tables 2-3). The values $\mathrm{R}^{2}$ are about equal to 1 reveal that model is best fitted for adsorption. Mckay studied the Elovich equation $(\mathrm{x} / \mathrm{m}) Q \mathrm{~m}=K \mathrm{EC} \mathrm{e}^{-((\mathrm{x} / \mathrm{m}) / \mathrm{Qm})}$ is effectively to explain the second order kinetics assuming that the real solid surfaces are heterogeneous energetically. The linear form is $\ln (x / m) / C \mathrm{e}=$ $\alpha(x / m)+\beta, Q m$ is the maximum quantity of the adsorbate adsorbed in the solid surface $(\mathrm{mg} / \mathrm{g})$, $k \mathrm{E}, \alpha$ and $\beta$ are the Elovich coefficients [24, 25].

Bull. Chem. Soc. Ethiop. 2017, 31(3) 

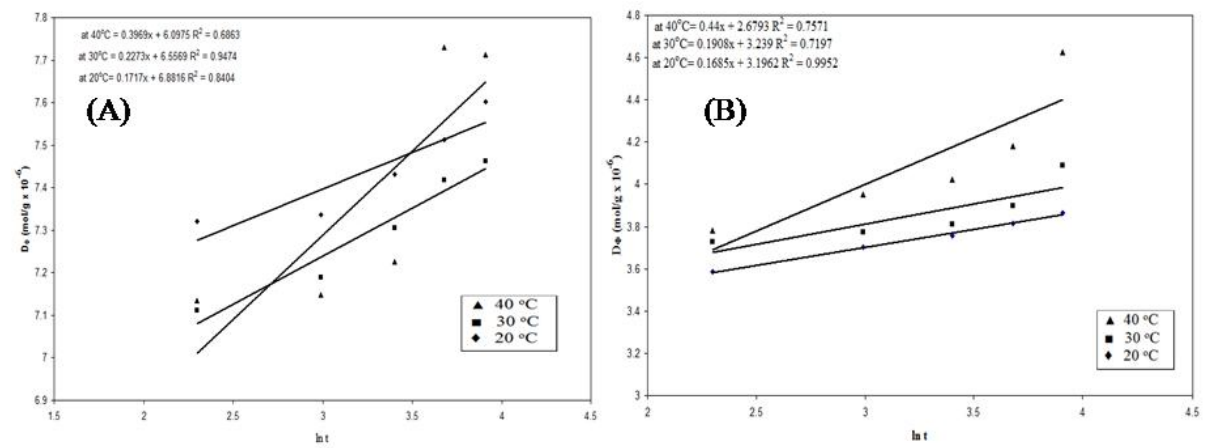

Figure 4. Elovich plots for adsorption of Basic Green 5 on (A) raw carbon and (B) activated carbon.

\section{Bangham equation}

Linear form of the Bangham equation is as.

$\log \log \frac{\mathrm{D}_{\circ}}{\mathrm{D}_{\circ}-\mathrm{D}_{\sigma} \mathrm{W}}=\log \frac{\mathrm{k} \cdot \mathrm{W}}{2.303 \mathrm{~V}}+\alpha \log \mathrm{t}$

Here, initial concentration is $D_{0}$, weight of dye is $W, V$ indicate volume of solution, $D_{\sigma}$ is quantity adsorbed at time t. Using the intercepts and slopes of linear plots shown in Figure 5. Values of $\mathrm{k}_{\mathrm{o}}$ and $\alpha$ are calculated (Tables 2-3). It is found that the shaking temperature increased the value of $\alpha$ decreased while $\mathrm{k}_{\mathrm{o}}$ increased with the raise in temperature showing the adsorption of dye in pores of carbon is well controlled process [26, 27]. Yaneva studied the experimental kinetic results were analyzed by series of rate/mass transfer equations. Bangham's model, Probably, 4-NP sorption was mainly limited by chemisorption, but the role of Bangham could not be neglected. The highest extend of 4-NP uptake determined in the recent study was $94 \%$ [28].
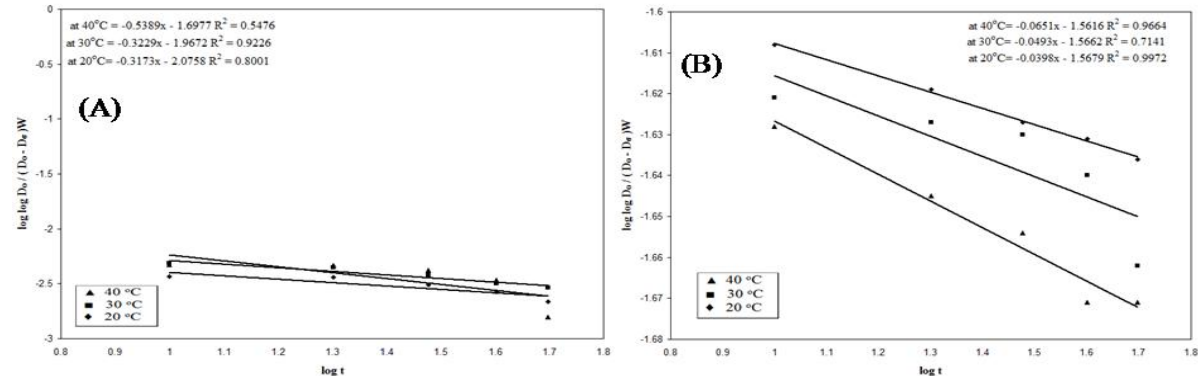

Figure 5. Bhangum plots for adsorption of Basic Green 5 on (A) raw carbon and (B) activated carbon. 


\section{Parabolic diffusion model}

The plots of $D_{\Phi}$ vs. $t^{1 / 2}$ show multi layer adsorption, which characterizes various steps counting in the adsorption [29]. According to Morris and Weber parabolic diffusion is given by:

$\mathrm{D}_{\Phi}=\mathrm{k}_{\mathrm{id}} \mathrm{t}^{1 / 2}+\mathrm{B}$
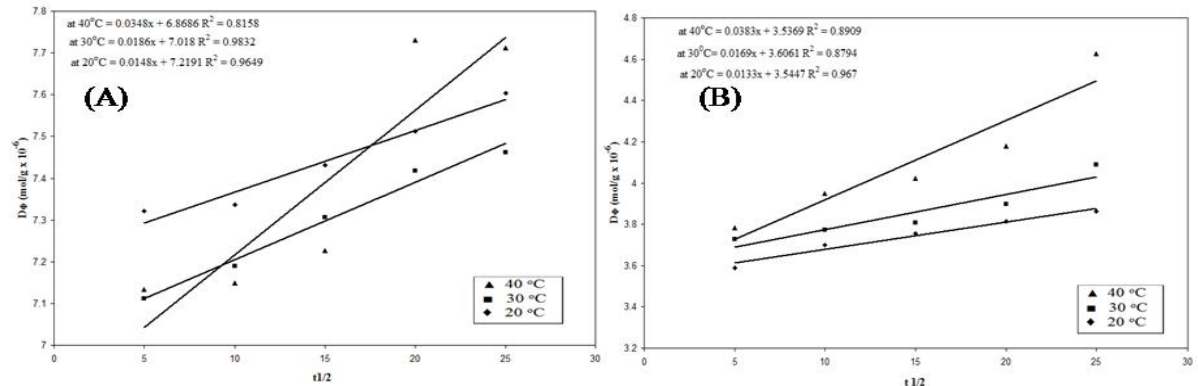

Figure 6. Intraparticle diffusion plots for adsorption of Basic Green 5 on (A) raw carbon and (B) activated carbon.

The intraparticle diffusion coefficient $\left(\mathrm{k}_{\mathrm{id}}\right)$ is given in Tables 2 and 3 . The $\mathrm{k}_{\mathrm{id}}$ values of BG-5 at $40{ }^{\circ} \mathrm{C}$ : 0.0383 for activated Eucalyptus lenceolata, 0.0348 for raw Eucalyptus lenceolata. The correlation coefficient $\mathrm{R}^{2}$ for the parabolic diffusion (0.999) is nearer to 1 confirms best agreement for the basic dye adsorption on carbon (Figure 6). This is due to the active sites on adsorbent surface. Yao studied intraparticle diffusion model for cyclic adsorption and desorption in a lab, cylinder or sphere is proposed on the basis of the asymptotic behavior of the adsorption rate for short and long cycle periods, through relationship with the accurate solution and the linear driving force (LDF) model [30].

\section{CONCLUSION}

The EDS spectra of both, raw and activated samples show the presence of carbon and oxygen. Moreover, the surface of raw sample contains potassium and calcium along with oxygen and carbon while the activated sample contains no such elements. The SEM micrograph show surface porosity in various size and shapes. The regions 1199,1190 and $1166 \mathrm{~cm}^{-1}$ in the spectra is due to the presence of $(\mathrm{C}-\mathrm{O})$ group stretching. Eucalyptus lenceolata show $\mathrm{C}=\mathrm{C}$ group present at 1614 and $1647 \mathrm{~cm}^{-1}$ in raw carbon. The activated carbon show $\mathrm{C}=\mathrm{O}$ band on 1716 , and $1697 \mathrm{~cm}^{-1}$. The presence of peak at $1022 \mathrm{~cm}^{-1}$ on activated carbon prepared from Eucalyptus lenceolata was due to the $\mathrm{S}=\mathrm{O}$ stretching. Surface area of raw sample was found to be $475 \mathrm{~m}^{2} \mathrm{~g}^{-1}$ while that of activated sample $399 \mathrm{~m}^{2} \mathrm{~g}^{-1}$. The greater surface area of the raw sample is due to the fact that its surface carries the elements, calcium and potassium while no such elements are found on the surface of activated sample. 4 hours is equilibrium time for whole surface coverage. The data indicate that the adsorption of dye on carbon particles is best fit to the linear equations and it was resulted that the process is a diffusion controlled process. The positive value of $\Delta \mathrm{H}^{\#}$ suggests the endothermic nature of adsorptive process. The negative values of $\Delta \mathrm{S}^{\#}$ suggest that the system is in order.

\section{ACKNOWLEDGEMENT}

The Department of Chemistry, University of Malakand and centralized resource Lab are highly acknowledged for providing the research facilities. 


\section{REFERENCES}

1. Gadkaree, K.P. Carbon honeycomb structures for adsorption applications. Carbon 1998, 36, 981-989.

2. Yates, M.; Blanco, J.; Avila, P.; Martin, M.P. Honeycomb monoliths of activated carbons for effluent gas purification. Micropor. Mesopor. Mater. 2000, 37, 201-208.

3. Castello, D.L.; Amoros, D.C.; Solana, A. Activated carbon monoliths for methane storage: Influence of binder. Carbon 2002, 40, 2817-2825.

4. Rai, H.S.; Singh, J.; Bhattacharyya, M.S.; Bansal, T.K.; Vats, P.; Banerjee, U.C. Removal of dyes from the effluent of textile and dyestuff manufacturing industry: A review of emerging techniques with reference to biological treatment. Crit. Rev. Environ. Sci. Technol. 2005, 35, 219-238.

5. Cherifi, H.; Fatiha, B.; Salah, H. Kinetic studies on the adsorption of methylene blue onto vegetal fiber activated carbons. Appl. Surf. Sci. 2013, 282, 52-59.

6. Angin, D.; Kose, T.E.; Selengil, U. Production and characterization of activated carbon prepared from safflower seed cake biochar and its ability to absorb reactive dyestuff. Appl. Surf. Sci. 2013, 280, 705-710.

7. Nouri, S.; Abad, R.M.D.; Bahram, M. Adsorption studies of $\beta$-naphthol by untreated and treated activated carbon optimizing of adsorption by central composite design (CCD). $J$. Iran Chem. Soc. 2012, 9, 397-405.

8. Caccin, M.; Giacobbo, F.; Ros, M.D.; Besozzi, L.; Mariani, M. Adsorption of uranium, cesium and strontium onto coconut shell activated carbon. Radioanal Nucl. Chem. 2013, 297, 9-18.

9. Ayranci, E.; Duman, O. Adsorption behaviors of some phenolic compounds onto high specific area activated carbon cloth. Hazard. Mater. 2005, 124, 125-132.

10. Shiau, C.; Pan, C. Adsorption of Basic dyes from aqueous solution by various adsorbents. Sep. Sci. Technol. 2004, 39, 1733-1750.

11. Qada, E.N.E.; Walker, G.M.; Allen, S.J. Adsorption of basic dyes from aqueous solution onto activated carbons. J. Chem. Eng. 2008, 135, 174-184.

12. Qasem, N.A.A.; El-Shaarawi, M.A.I. Improving ice productivity and performance for an activated carbon/methanol solar adsorption ice-maker. Sol. Energy 2013, 98, 523-542.

13. Roosta, M.; Ghaedi, M.; Daneshfar, A.; Sahraei, R. Spectrochim. Acta Part A: Mol. Biomol. Spectrosc. 2014, 122, 223-231.

14. Pradhan. K.B.; Sandle, N.K. Effect of oxidizing agents treatments on the surface properties of activated carbon. Carbon 1999, 37, 1323-1332.

15. Eisazadeh, A.; Eisazadeh, H. N2-BET surface area and FESEM studies of lime-stabilized montmorillonitic and kaolinitic soils. Environ. Earth Sci. 2015, 74, 377-384.

16. Goldstein, J.; Newbury, D.; Joy, D.; Lyman, C.; Echlin, P.; Lifshin, E.; Sawyer, L.; Michael, J. Scanning Electron Microscopy and X-ray Microanalysis, 3rd ed., Springer: New York; 2003; pp. 1-20.

17. Cooke, N.E.; Fuller, O.M.; Gaikwad, R.P. FTIR spectroscopic analysis of coal and coal extracts. Fuel 1986, 65, 1254-1259.

18. Younas, M. Organic Spectroscopy, AHP International: Lahore, 1998.

19. Khare, P. Treatment of phenolic water using adsorption, MTech Thesis, National Institute of Technology, Rourkela, India, 2011.

20. Ho, Y.S.; Chiang, T. H.; Hsueh, Y.M. Removal of basic dye from aqueous solution using tree fern as a biosorbent. Process Biochem. 2005, 40, 119-124.

21. Laidler, K.L. Chemical Kinetics, Mc-Graw Hill: New York; 1965.

22. El-Khaiary, M.I.J. Kinetics and mechanism of adsorption of methylene blue from aqueous solution by nitric-acid treated water-hyacinth. Hazard. Mater. 2007, 147, 28-36. 
23. Sharma, K.K.; Sharma, K.L.A Text Book of Physical Chemistry, Vikas Publishing House: New Delhi; 1992.

24. Mckay, G.; Blair, H.S.; Gardener, J. R. Adsorption of dyes on chitin. I: Equilibrium studies. J. Appl. Polym. Sci. 1982, 27, 3043-3056.

25. Thomas, J.M.; Thomas, W.J. Principle and Practice of Heterogeneous Catalysis, VCH: Weinhem; 1997.

26. Aharoni, C.; Sideman, S.; Hoffer, E. Adsorption of phosphate ions by colloid ion-coated alumina. J. Chem. Technol. Biotechnol. 1979, 29, 404-412.

27. Qadeer, R.; Hanif, J.; Saleem, M.; Afzal, M. Kinetics and thermodynamics of some metal ions adsorption on activated charcoal from aqueous solution. J. Chem. Soc. Pak. 1995, 17, 82-86.

28. Yaneva, Z.L.; Koumanova, B.K.; Allen, S.J. Applicability comparison of different kinetic/diffusion models for 4-nitrophenol sorption on Rhizopus oryzae dead biomass. Bulg. Chem. Commun. 2013, 45, 161-168.

29. Vadivelan, V.; Kumar, K.V. Equilibrium, kinetics, mechanism, and process design for the sorption of methylene blue onto rice husk. Colloid Interf. Sci. 2005, 286, 90-100.

30. Yao, C. A new intraparticle mass transfer rate model for cyclic adsorption and desorption in a slab, cylinder or sphere. Adsorption 2013, 19, 77-81. 